\title{
Research Progress on Chemical Modification and Application of Cellulose: A Review
}

\author{
Jinjie ZHANG ${ }^{1}$, Yingping $\mathrm{QI}^{2}$, Yongfeng $\mathrm{SHEN}^{2}$, Hua $\mathrm{LI}^{1}{ }^{*}$ \\ ${ }^{1}$ School of Chemical Engineering, Zhengzhou University, No. 100 Science Road, Zhengzhou, Henan, China \\ ${ }^{2}$ Zhengzhou Museum, No. 168 Songshan South Road, Zhengzhou, Henan, China \\ crossref http://dx.doi.org/10.5755/j02.ms.25485
}

Received 17 March 2020; accepted 18 June 2020

\begin{abstract}
Cellulose is a rich natural polymer material, which has the characteristics of biodegradability, environmental friendliness and good biocompatibility. However, compared with conventional materials, there are some shortcomings in performance, such as intolerance corrosion, limited strength and so on. The chemical modification of cellulose not only retains its own excellent characteristics, but also introduces functional groups to endow it with specific properties. The chemical modification and utilization of cellulose has been the focus of research. In this paper, the latest advances in chemical modification of cellulose, such as esterification, etherification and grafting modification, are introduced. The research and application results of cellulose derivatives in food, wastewater treatment, medicine and papermaking in recent years are reviewed. Keywords: cellulose, modified cellulose, chemical modifications, applications.
\end{abstract}

\section{INTRODUCTION}

Polymer materials based on fossil resources have become an indispensable part of industry and people's daily life because of their excellent durability, high strength and easy processing. However, due to the resource and environmental problems caused by their non-renewability and non-biodegradability, people have a clear understanding of the importance and necessity of developing natural polymer-based materials [1,2]. Cellulose is the most abundant natural polymer material on the earth, and it is cheap and has a wide range of sources. It has the characteristics of biodegradability, good biocompatibility and broad chemical modifying capacity $[3,4]$.

The structure of natural cellulose is characterized by many hydrogen bonds within and between molecules and high crystallinity, which makes it insoluble in water and general organic solvents, which greatly limits the utilization of cellulose. Therefore, the modification of cellulose to expand the utilization of cellulose has become an urgent problem to be solved, and chemical modification of cellulose is the most common method. The microstructure of cellulose is that there are three active hydroxyl groups on the D-pyrane glucose unit (AGU): one primary hydroxyl group (C-6) and two secondary hydroxyl groups (C-2 and C-3), which can undergo a series of derivatization reactions related to hydroxyl groups, such as etherification, esterification, crosslinking, graft copolymerization and so on [5, 6]. In particular, cellulose can be chemically modified to improve its solubility and stability, giving it new functions such as light, electricity, magnetism, biological activity, adsorption, separation and catalysis. In recent decades, the research of new cellulose-based materials has developed rapidly, such as cellulose fibers [7, 8], cellulose hydrogels and aerogels [9-11], cellulose membranes $[12,13]$, cellulose microspheres [14, 15], cellulose nanomaterials [16, 17]. These different functional cellulose materials are widely used in many fields of modern industry. This paper mainly introduces the research and progress of chemical modification of cellulose, summarizes the research progress of the application of cellulose derivatives in recent years, and prospects its future development.

\section{CHEMICAL MODIFICATION OF CELLULOSE}

\subsection{Esterification modification of cellulose}

Cellulose ester refers to the product of esterification reaction between hydroxyl group on the molecular chain of cellulose and acid, acid anhydride, acyl halide under the catalysis of acid [18]. Cellulose esters, as the earliest research and production of cellulose derivatives in cellulose chemistry, are widely used in textile, medicine, coatings, film science, petrochemical industry and other fields [19]. The high degree of crystallization and hydrogen bonding within and between molecules of cellulose prevents it from dissolving in general organic and inorganic solvents. Due to the lack of excellent cellulose solvents, commercial cellulose esters are currently synthesized by heterogeneous methods. The studies showed that heterogeneous system could not control the reaction process well, which was disadvantageous to the esterification of cellulose and had low degree of substitution; however, homogeneous system could improve the esterification reaction speed of cellulose and reduce the disaggregation of the main chain of cellulose $[3,20]$. Therefore, it is urgent to find an effective

\footnotetext{
* Corresponding author. Tel.: +086-13653860337.

E-mail address: lihua@zzu.edu.cn (H. Li)
} 
homogeneous esterification system for further optimization of cellulose esters. Lithium chloride/N, N-dimethyl acetamide ( $\mathrm{LiCl} / \mathrm{DMAc}$ ) and ionic liquid are effective solvents of cellulose with advantages of recyclability and good thermal stability [21]. Meanwhile, the dissolution of cellulose in homogeneous system facilitates the introduction of functional groups, which widens the way for the application of cellulose esters.

Willberg-Keyriläinen et al. [22] dissolved cellulose in $5 \% \mathrm{LiCl} / \mathrm{DMAc}$ solution, then fatty acid chlorides with different side chain lengths (C6-C18) were added to the cellulose solution to prepare a series of cellulose esters. Then cellulose esters were coated on CNF films to form a 3layer film (ester-CNF-ester). The 3-layer films have smooth surface, good mechanical properties and water vapor barrier. Based on the excellent properties of membrane materials, it has potential application value in the field of food packaging and electronic printing. Gu et al. [23] used bleached hardwood cellulose as raw material, 1-butyl-3methylimidazolium chloride $(\mathrm{BmimCl})$ ionic liquid as reaction medium, and reacted with $\varepsilon$-caprolactone monomer to prepare cellulose-polycaprolactone graft copolymer (cellulose-g-PCL) from under homogeneous conditions. The poly-caprolactone graft copolymer has a maximum graft ratio of $86.7 \%$.

\subsection{Etherification modification of cellulose}

Cellulose ether is a series of cellulose derivatives produced by the reaction of alkaline cellulose and etherifying agent under certain conditions. It is the product of partial or total substitution of hydroxyl groups on cellulose macromolecules by ether groups. Cellulose ether is a cellulose derivative widely used and with high added value. It has important applications in textile, membrane science, biological materials and environmental protection [24-26]. With the development of cellulose ether research, cellulose ether with good reaction system or excellent performance has been developed gradually. Nagel et al. [27] synthesized methylcellulose (MC) in homogeneous phase using $\mathrm{LiOH} /$ urea system as reaction medium and dimethyl sulfate as etherifying agent. He first slowly dripped etherifying agent at $0{ }^{\circ} \mathrm{C}$, then heated it to $22{ }^{\circ} \mathrm{C}$ and stirred it for 24 hours. The product was precipitated and washed with isopropanol. The DS of the product was $1.07-1.59$. Li et al. [28] used acrylonitrile (AN) as etherifying agent to synthesize a series of cyanoethyl celluloses with degree of substitution (DS) in LiOH/urea aqueous solution. The highest DS of CEC was 1.81. CEC samples with DS ranging from 0.47 to 1.01 have good water solubility, and those with DS greater than 1.12 can be better soluble in organic solvents. Dong et al. [29] used microcrystalline cellulose (MCC) and 5-bromo-pent-1-ene as the main raw materials, in the action of sodium hydride and ethyl iodide, one pot method was used to synthesize ethyl pent-4-enyl cellulose, and then a series of amorphous solid dispersed amphiphilic cellulose ethers were obtained by olefin cross-metathesis reaction using ethyl pent-4-enyl cellulose and acrylic acid or acrylate monomer as raw material. The synthetic steps of amphiphilic cellulose ether are shown in Fig. 1. These amphiphilic polymers have potential applications in drug delivery and waterborne coatings.

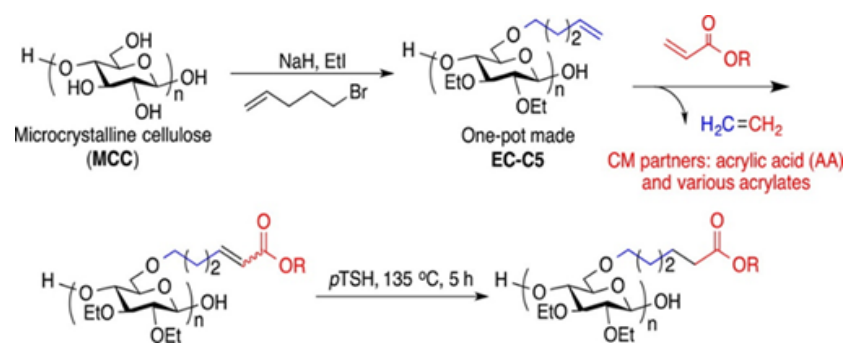

Fig. 1. The synthetic of amphiphilic cellulose ether. Reproduced with the permission of Ref. [29], copyright (2016) American Chemistry Society

\subsection{Grafting modification of cellulose}

The graft copolymerization of cellulose is based on the active hydroxyl group on the molecular chain as a grafting point. Under the condition of not completely destroying the advantages of cellulose materials, the polymer chain formed by the polymerization reaction of the monomer is grafted onto the cellulose main chain through covalent bond, giving cellulose new properties. The common methods of graft copolymerization are free radical polymerization, ringopening polymerization, ionic polymerization and atom transfer free radical polymerization. And it is implemented mainly in the following three ways (Fig. 2): "grafting through", "grafting to" and "grafting from". The most commonly used method is "grafting from". Due to the small molecular monomers involved in the reaction and the small steric resistance, this method is easier to synthesize cellulose graft copolymers with high graft ratio [30, 31].

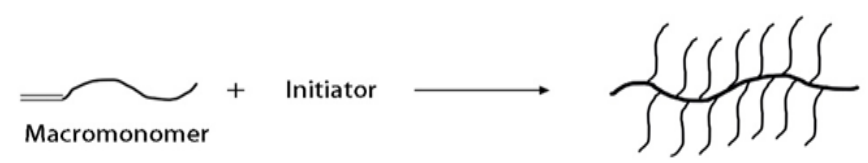

a

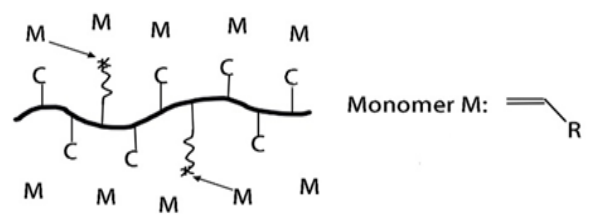

b

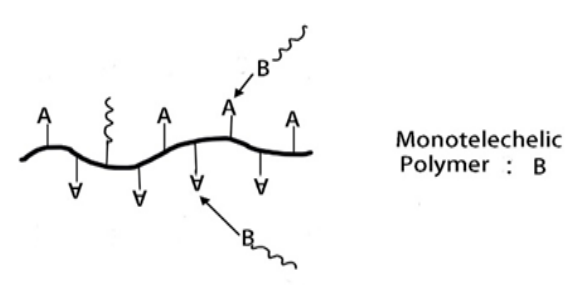

C

Fig. 2. Three main ways of graft copolymerization of cellulose: a - grafting through; b - grafting from; c - grafting to [30]

The characteristics of graft copolymerization are that monomers are copolymerized to form polymer chains, and then grafted onto the main chain of cellulose in the form of covalent bonds. Common monomers are acrylonitrile, acrylic acid, acrylamide, methyl methacrylate and so on. 
Nourelhoda et al. [32] successfully grafted acrylic acid (AA) and acrylamide (AAm) onto cellulose acetate (CA) matrix [CA-g-(AA-Co-AAm)] by atomic radical polymerization, and studied the absorption of lead ions in wastewater by CA and modified CA. The results showed that the latter greatly increased the adsorption capacity of $\mathrm{Pb}(\mathrm{II})$ ions, reaching $66.67 \mathrm{mg} / \mathrm{g}$. Jiang et al. [33] first synthesized a new cellulose-based polymer chain transfer agent (Cell-CTA) with cellulose 2-bromoisobutyrylate (Cell-BiB) and 1-dodecanethiol as raw materials, and then grafted n-butyl acrylate (BA) and acrylamide (AM) onto Cell-CTA by reversible addition-fragmentation chain transfer (RAFT) polymerization to prepare cellulose graft copolymer (Cell-g-P(BA-co-AM)) with good mechanical properties.

\subsection{Other modification methods}

In addition to the above modification methods, chemical modification of cellulose also includes oxidation modification and cross-linking modification.

The oxidation of cellulose can be divided into selective oxidation and non-selective oxidation. The non-selective oxidation oxidants include hydrogen peroxide, sodium hypochlorite and persulfuric acid. The selective oxidants can be directed to oxidize the hydroxyl groups of cellulose to obtain cellulose derivatives with specific structures [34]. Wen et al. [35] used an eco-friendly oxidation process that combines ultraviolet light, hydrogen peroxide and ozone to deoxidize cellulose. The synthesis steps of oxidized cellulose are shown in Fig. 3. Then the oxidized cellulose was homogenized under high pressure to prepare nano cellulose fibers (CNFs). The average length and width of CNFs prepared by this environment-friendly method can reach $11 \mu \mathrm{m}$ and $22 \mathrm{~nm}$ respectively, which makes the obtained high-quality CNFs have great application potential.

Crosslinking modification of cellulose refers to the use of crosslinking agents (such as N,N'-methylene bisacrylamide (MBA), epichlorohydrin (ECH)) to connect cellulose or cellulose derivatives with other polymers to form three-dimensional network structure products, which is commonly used in drug-controlled release, membrane science and other fields.

\section{APPLICATIONS OF CELLULOSE DERIVATIVES}

Cellulose and its derivatives can be widely used in different important fields such as food industry, water treatment industry, pharmaceutical industry, paper industry. The following part mainly reviews the application of chemically modified functional cellulose.

\subsection{Application of food industry}

The development of edible and biodegradable materials is an important research topic in the field of food science. Cellulose has the advantages of easy to make, non-toxic, renewable, biocompatible, so cellulose and cellulose derivatives have long been widely used in the food industry $[3,36]$.

One of its important applications is to modify cellulose to form film for food packaging. Singh et al. [37] used sodium carboxymethyl cellulose (CMC) and hydroxyethyl cellulose (HEC) as membrane materials and crosslinked with citric acid under certain conditions to prepare a new cellulose-based edible film. They selected Lactobacillus rhamnosus GG (LGG) as the model probiotic bacteria and studied the viability of LGG encapsulated with cellulosebased film. The results showed that the films could effectively preserve live LGG. Overall, the cellulose-based edible films have a bright application prospect in the field of food protection and packaging. Jamaluddin et al. [38] used cellulose nanofiber as a raw material to obtain acetylated cellulose nanofiber (ACNF) by grafting hydroxyl group on the main chain of cellulose with acetic anhydride. Then, PLA/ACNF films were prepared by filling poly(lactic acid) (PLA) with ACNF as filler. Because of its strong hydrophobicity, good compatibility and good mechanical properties, the film has broad prospects in bio-based food packaging.

Considering safety and sustainable development, cellulose derivatives can also be used as thickeners. Gao et al. [39] first extracted cellulose from brown algae (BA), and then obtained BA cellulose nanofibers (BACNFs) through a series of treatments such as oxidation. They studied the rheological behavior of BACNFs in water and the thickening performance of nanofibers added to milk.

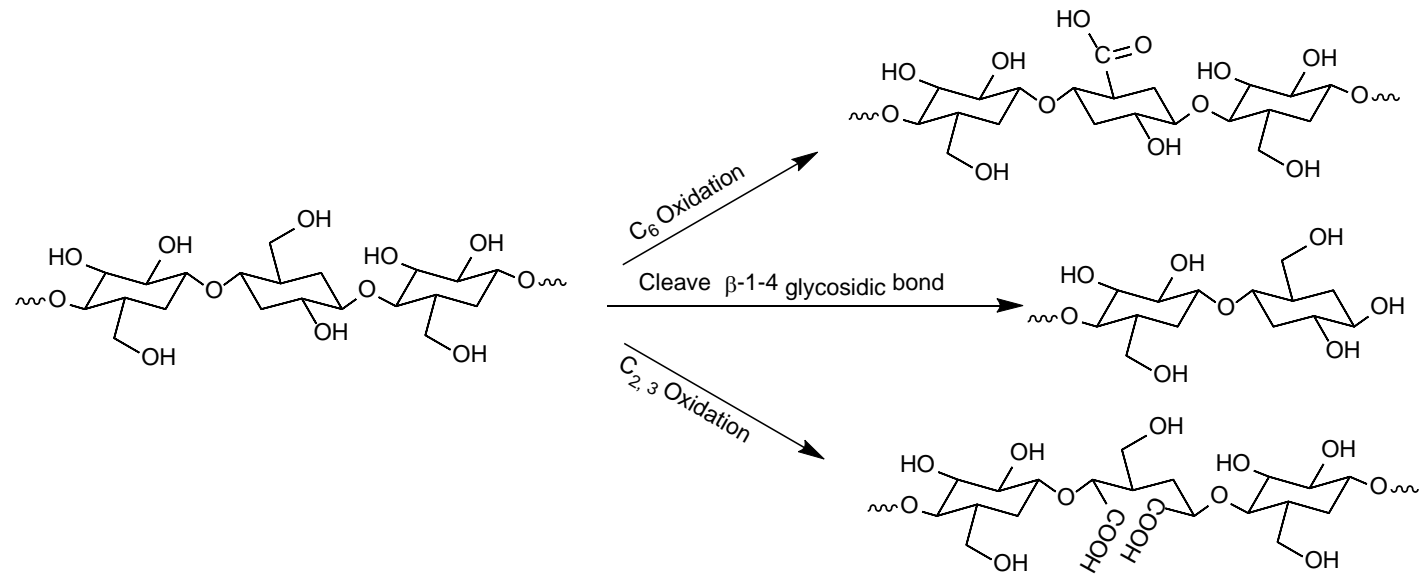

Fig. 3. Schematic diagram of cellulose oxidation. Reproduced with the permission of ref. [35], copyright (2020) American Chemistry Society 
When nanofibers were added to milk, the nanofibers formed weak gelatinous structure through hydrogen bond adsorption, achieving the effect of thickening. Cell viability test showed that BACNFs had good biocompatibility and biological activity. Based on the above characteristics, fiber materials can be used as a good thickener in the food industry. In addition, cellulose derivatives can also be used in food industry as emulsifier [40], stabilizer [41] and expander [42].

\subsection{Application of wastewater treatment}

The rapid development of industry and the surge of population in recent decades have caused serious environmental pollution, and the treatment of water pollution has become one of the urgent problems to be solved. In recent years, in the field of wastewater treatment, cellulose-based derivatives have attracted extensive attention due to their advantages of renewable, low-cost, non-toxic side effects, large absorption [43, 44].

In order to find an excellent dye wastewater adsorbent, Gopakumar et al. [45] synthesized a new type of green adsorption material by the reaction of cellulose nanofiber (CNF) and Meldrum's acid as esterification agent. The synthesis equation is shown in Fig. 4. The experiment verified that the modified cellulose nanofiber can adsorb positively charged crystal violet dye. In order to increase its adsorption and filtration performance, they also coated modified cellulose nanofiber on polyvinylidene fluoride electrospun membrane, thereby obtaining a high degree of simultaneous removal of crystal violet dye and nano-sized $\mathrm{Fe}_{2} \mathrm{O}_{3}$ in water.

A novel efficient cellulose grafting adsorbent was prepared by dispersing a certain proportion of clay and cellulose mixture in distilled water and grafting vinyl monomers onto the main chain of cellulose with potassium persulfate (PPS) as initiator [46]. Experiments showed that the adsorbent had good removal effect on $\mathrm{Ca}, \mathrm{Mg}, \mathrm{Fe}, \mathrm{Pb}$, and $\mathrm{Cu}$ ions individually in aqueous solution. The effectiveness and low cost of the cellulose based adsorbent show its potential for large-scale application in the field of water treatment.

Zhang et al. [47] used sodium periodate to selectively oxidize the hydroxyl of cellulose at C-2 and C-3 positions to obtain 2,3-dialdehyde cellulose (DAC), and then reacted DAC with polyethylene imine (PEI) to form hyperbranched polyethylenimine-grafted cellulose (hPEI-CE) flocculant with Schiff base structure.
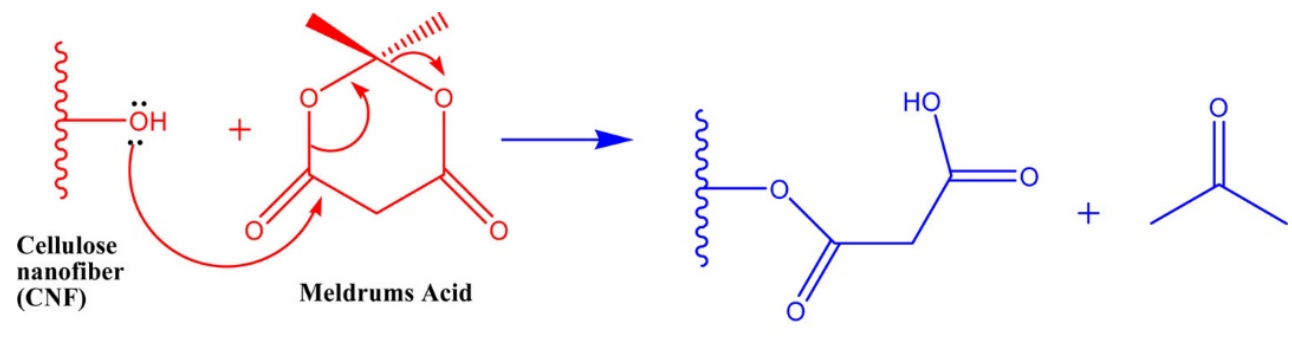

CNF (Acid Form)

Fig. 4. Strategy for the preparation of the Meldrum's acid modified cellulose nanofiber. Reproduced with the permission of Ref. [45], copyright (2017) American Chemistry Society

CE $\quad$ DAC

DAC hPEI-CE

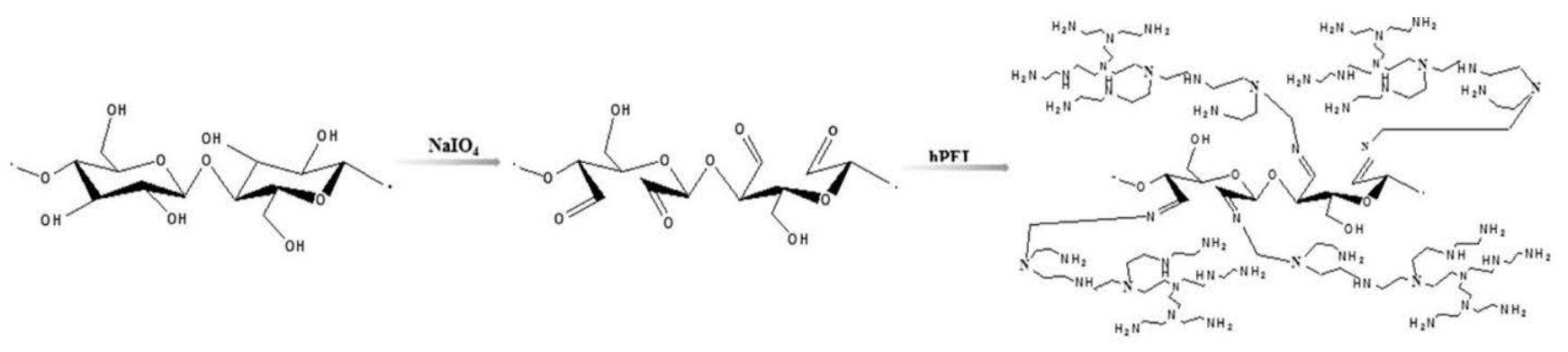

a
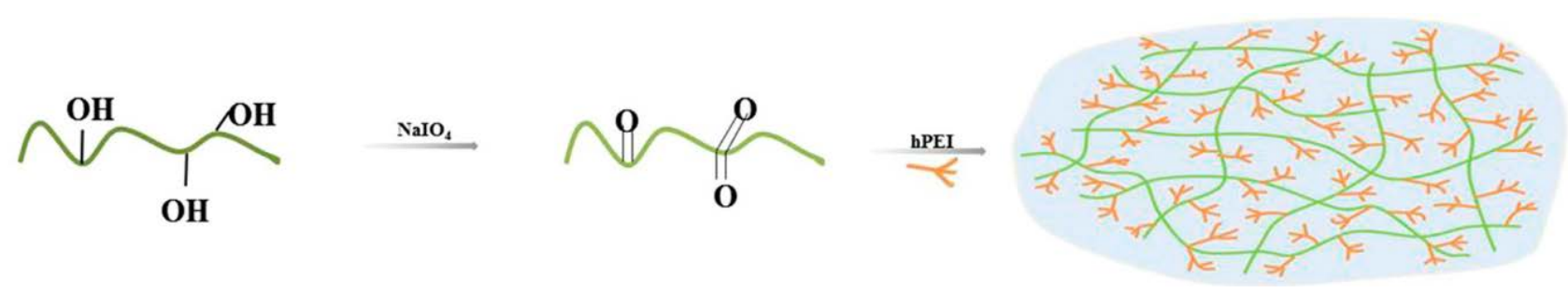

b

Fig. 5. Schematic diagram of hPEI-CE synthesis. Reproduced with the permission of ref. [47], copyright (2018) American Chemistry Society 
The synthesis steps are shown in Fig. 5. The flocculation effect of the flocculant was evaluated by applying the flocculant to the treatment of silk dyeing wastewater and machining wastewater. Experiments showed that the flocculant with lower dosage can achieve better flocculation performance. For example, the removal rate of turbidity and total suspended solids can reach $97.8 \%$ and $99.1 \%$ respectively. Based on its better flocculation performance, the flocculant obtained by the modification of natural polymer has a bright application prospect in wastewater treatment.

As wastewater treatment is still one of the problems that must be solved in the future, cellulose derivatives have attracted more and more researchers' attention because of their low price, abundant reserves and degradability.

\subsection{Application of paper industry}

Cellulose paper is a kind of biodegradable material, which is widely used in people's life because of its low cost and mass production. In the paper industry, cellulose derivatives can improve the physical properties of paper, such as strength, folding resistance and tearing resistance. With the increasing demand for high-performance paper and functional paper, cellulose derivatives are often used as paper reinforcers, surface sizing agents, water retaining agent and stabilizers in paper industry [52 - 54].

Cellulose derivatives can be introduced into the pulp to obtain different functions of the paper, such as paper with uniform ink absorption and high adhesion, or paper with hydrophobic and antibacterial properties. In order to develop functional paper, El-Wakil et al. [55] prepared hydroxypropyl cellulose/oxidized cellulose nanocrystals nanocomposites, which were coated on paper to improve the tensile strength and reduce the porosity of paper. and the mixed solution was applied to paper to obtain an environmentally-friendly wrapping paper which has water and oil resistance and has a bactericidal action against Escherichia coli. Shankar et al. [56] used carboxymethyl cellulose, and carrageenan alginate and grapefruit seed extract as raw material to prepare mixed polymer coating solution. The mixed solution was coated on paper, and a kind of environmentally-friendly packaging paper with water and oil resistance and bactericidal effect on Listeria monocytogenes and Escherichia coli was obtained.

Modified cellulose not only has some characteristics of cellulose itself, but also has the new characteristics given by the modification. It will have great application prospects in the paper industry, open up a new way for the utilization of plant resources, and also bring great economic and social benefits to the paper industry.

Table 1 summarizes some cellulose derivatives modified by different methods and their applications. Some cellulose-based materials obtained by etherification, graft copolymerization and other methods have good biodegradability, non-toxic and harmless, so they are widely used in the pharmaceutical industry. Cellulose can be grafted with some polar monomers by free radical polymerization to obtain the adsorption effect on metal ions. It can be seen that the chemically modified cellulose has obtained new functions, which are widely used in food, medicine, water treatment and other fields.

\section{CONCLUSIONS}

Facing the severe challenges of energy and environment, the research and development of cellulose has become one of the important topics of global sustainable development. Cellulose is a green and environment-friendly natural polymer, and large yield, wide source and renewable, with good biocompatibility, mechanical properties and other advantages. However, its structural characteristics, poor solubility and intolerance corrosion limit its application. Fortunately, the chemical modification of cellulose not only retains its own excellent characteristics, but also introduces functional groups to endow it with specific properties. At present, chemically modified cellulose is widely used in different fields such as food industry, water treatment industry, pharmaceutical industry and paper industry. We expect extensive applications of chemically modified cellulose in the near future.

Table 1. Modified cellulose materials and their applications

\begin{tabular}{|c|c|c|c|}
\hline Method & Product ${ }^{\mathrm{a}}$ & Application & Ref. \\
\hline \multirow{3}{*}{ Esterification modification } & Long chain cellulose ester & Potential packaging and printing electronics applications & [22] \\
\hline & Cellulose-g-PCL & Potential drug carrier applications & [23] \\
\hline & Cellulose-g- $\beta-C D$ & Drug carrier & [51] \\
\hline Etherification modification & Pent-4-enyl cellulose & $\begin{array}{l}\text { Potential applications in drug delivery and waterborne } \\
\text { coatings }\end{array}$ & [29] \\
\hline \multirow{2}{*}{ Grafting modification } & CA-g-(AA-co-AAm) & Pb ion adsorption & [32] \\
\hline & CE-PAA & Biomedical application & [50] \\
\hline \multirow{2}{*}{ Other } & CMC/HEC composite film & Food protection and packaging & [37] \\
\hline & BACNFs & Milk thickeners & [39] \\
\hline \multicolumn{4}{|c|}{$\begin{array}{l}\text { a Long chain cellulose ester, long chain fatty acid chlorides modified cellulose; Cellulose-g-PCL, cellulose-graft-polycaprolactone; } \\
\text { Cellulose-g- } \beta \text {-CD, } \beta \text {-cyclodextrin modified cellulose; Pent-4-enyl cellulose, 5-bromo-pent-1-ene modified microcrystalline cellulose; } \\
\text { CA-g-(AA-co-AAm), cellulose acetate-graft-(acrylic acid-co-acrylamide); CE-PAA, cellulose ethers grafted poly(acrylic acid); } \\
\text { CMC/HEC composite film, citric acid crosslinked carboxymethyl cellulose and hydroxyethyl cellulose; BACNFs, brown algae } \\
\text { cellulose nanofibers obtained by oxidation of alginate cellulose. }\end{array}$} \\
\hline
\end{tabular}




\section{REFERENCES}

1. Moon, R.J., Martini, A., $\quad$ Nairn, J., $\quad$ Simonsen, J., Youngblood, J. Cellulose Nanomaterials Review: Structure, Properties and Nanocomposites Chemical Society Reviews 40 (7) 2011: pp. 3941 - 3994. https://doi.org/10.1039/c0cs00108b

2. Wang, S., Lu, A., Zhang, L. Recent Advances in Regenerated Cellulose Materials Progress in Polymer Science 53 2016: pp. 169-206. https://doi.org/10.1016/j.progpolymsci.2015.07.003

3. Klemm, D., Heublein, B., Fink, H., Bohn, A. Cellulose: Fascinating Biopolymer and Sustainable Raw Material Angewandte Chemie (International ed. in English) 44 (22) 2005: pp. $3358-3393$. https://doi.org/10.1002/anie.200460587

4. Xu, Q., Chen, C., Rosswurm, K., Yao, T., Janaswamy, S. A Facile Route to Rrepare Cellulose-based Films Carbohydrate Polymers 149 2016: pp. 274-281. https://doi.org/10.1016/j.carbpol.2016.04.114

5. Klemm, D., Philpp, B., Heinze, T., Heinze, U., Wagenknecht, W. Comprehensive Cellulose Chemistry: Fundamentals and Analytical Methods Carbohydrate Polymers 43 (2) 2000: pp. 206-207. https://doi.org/10.1016/S0144-8617(00)00162-4

6. Courtenay, J.C., Johns, M.A., Galembeck, F., Deneke, C., Lanzoni, E.M., Costa, C.A., Scott, J., Sharma, R.I. Surface Modified Cellulose Scaffolds for Tissue Engineering Cellulose 24 (1) 2017: pp. 253-267.

https://doi.org/10.1007/s10570-016-1111-y

7. Li, X., Zhang, K., Shi, R., Ma, X., Tan, L., Ji, Q., Xia, Y. Enhanced Flame-retardant Properties of Cellulose Fibers by Incorporation of Acid-resistant Magnesium-oxide Microcapsules Carbohydrate Polymers 176 2017: pp. $246-256$. https://doi.org/10.1016/j.carbpol.2017.08.096

8. Rananavare, A.P., $\quad$ Kadam, S.J., $\quad$ Prabhu, S.V., Chavan, S.S., Anbhule, P.V., Dongale, T.D. Organic Nonvolatile Memory Device Based on Cellulose Fibers Materials Letters 232 2018: pp. 99-102. https://doi.org/10.1016/j.matlet.2018.08.091

9. Geng, $\mathbf{H}$. Preparation and Characterization of Cellulose/N,N'-methylene Bisacrylamide/Graphene Oxide Hybrid Hydrogels and Aerogels Carbohydrate Polymers 196 2018: pp. 289-298. https://doi.org/10.1016/j.carbpol.2018.05.058

10. Zhang, Y., Yin, M., Lin, X., Ren, X., Huang, T., Kim, I.S. Functional Nanocomposite Aerogels Based on Nanocrystalline Cellulose for Selective Oil/Water Separation and Antibacterial Applications Chemical Engineering Journal 371 2019: pp. 306-313. https://doi.org/10.1016/j.cej.2019.04.075

11. Matsuyama, K., Morotomi, K., Inoue, S., Nakashima, M., Nakashima, H., $\quad$ Okuyama, T., Kato, T., Muto, H., Sugiyama, H. Antibacterial and Antifungal Properties of Ag Nanoparticle-loaded Cellulose Nanofiber Aerogels Prepared by Supercritical $\mathrm{CO}_{2}$ Drying The Journal of Supercritical Fluids 143 2019: pp. 1-7. https://doi.org/10.1016/j.supflu.2018.08.008

12. Ibrahim, Y., Abdulkarem, E., Naddeo, V., Banat, F., Hasan, S.W. Synthesis of Super Hydrophilic Cellulosealpha Zirconium Phosphate Ion Exchange Membrane Via Surface Coating for the Removal of Heavy Metals from Wastewater Science of The Total Environment 690 2019: pp. $167-180$.

https://doi.org/10.1016/j.scitotenv.2019.07.009
13. Cai, Z., Li, R., Xu, X., Sun, G., Zhuang, X., Liu, Y., Cheng, B. Embedding Phosphoric Acid-doped Cellulose Nanofibers into Sulfonated Poly(ether sulfone) for Proton Exchange Membrane Polymer 156 2018: pp. 179-185. https://doi.org/10.1016/j.polymer.2018.10.013

14. Wang, F., Zhang, Q., Li, X., Huang, K., Shao, W., Yao, D., Huang, C. Redox-responsive Blend Hydrogel Films Based on Carboxymethyl Cellulose/Chitosan Microspheres as Dual Delivery Carrier International Journal of Biological Macromolecules 134 2019: pp. 413-421. https://doi.org/10.1016/j.ijbiomac.2019.05.049

15. Fan, L., Lu, Y., Yang, L., Huang, F., Ouyang, X. Fabrication of Polyethylenimine-functionalized Sodium Alginate/Cellulose Nanocrystal/Polyvinyl Alcohol Coreshell Microspheres ((PVA/SA/CNC)@PEI) for Diclofenac Sodium Adsorption Journal of Colloid and Interface Science 554 2019: pp. 48-58. https://doi.org/10.1016/j.jcis.2019.06.099

16. Ghasemi, S., Tajvidi, M., Bousfield, D.W., Gardner, D.J. Reinforcement of Natural Fiber Yarns by Cellulose Nanomaterials: A Multi-scale Study Industrial Crops and Products 111 2018: pp. 471-481. https://doi.org/10.1016/j.indcrop.2017.11.016

17. Lv, P., Xu, W., Li, D., Feng, Q., Yao, Y., Pang, Z., Lucia, L.A., Wei, Q. Metal-based Bacterial Cellulose of Sandwich Nanomaterials for Anti-oxidation Electromagnetic Interference Shielding Materials \& Design 112 2016: pp. 374-382. https://doi.org/10.1016/j.matdes.2016.09.100

18. Gao, C., Liu, S., Edgar, K.J. Regioselective Chlorination of Cellulose Esters by Methanesulfonyl Chloride Carbohydrate Polymers 193 2018: pp. 108-118. https://doi.org/10.1016/j.carbpol.2018.03.093

19. Edgar, K.J., $\quad$ Buchanan, C.M., Debenham, J.S., Rundquist, P.A., Seiler, B.D., Shelton, M.C., Tindall, D. Advances in Cellulose Ester Performance and Application Progress in Polymer Science 26 (9) 2001: pp. 1605-1688. https://doi.org/10.1016/S0079-6700(01)00027-2

20. Cao, Y., Li, H., Zhang, J. Homogeneous Synthesis and Characterization of Cellulose Acetate Butyrate (CAB) in 1Allyl-3-Methylimidazolium Chloride (AmimCl) Ionic Liquid Industrial \& Engineering Chemistry Research 50 (13) 2011: pp. 7808-7814. https://doi.org/10.1021/ie2004362

21. Yan, C., Wu, J., Zhang, J., Li, H., Zhang, Y., He, J. Room Temperature Ionic Liquids (RTILs): A New and Versatile Platform for Cellulose Processing and Derivatization Chemical Engineering Journal 147 (1) 2009: pp. 13 - 21. https://doi.org/10.1016/j.cej.2008.11.011

22. Willberg-Keyriläinen, P., $\quad$ Vartiainen, J., $\quad$ Pelto, J., Ropponen, J. Hydrophobization and Smoothing of Cellulose Nanofibril Films by Cellulose Ester Coatings Carbohydrate Polymers 170 2017: pp. 160-165. https://doi.org/10.1016/j.carbpol.2017.04.082

23. Gu, L., Li, Y., Yang, Y., Jin, Y. Synthesis and Characterization of Cellulose-Graft-PCL Using an Ionic Liquid as a Reaction Medium Journal of Cellulose Science and Technology 25 2017: pp. $32-38$. https://doi.org/10.16561/j.cnki.xws.2017.03.08

24. Hurnaus, T., Plank, J. Adsorption of Non-ionic Cellulose Ethers on Cement Revisited Construction and Building Materials 195 2019: pp. 441-449. https://doi.org/10.1016/j.conbuildmat.2018.11.020

25. Wang, L., Fu, Q., Yu, J., Liu, L., Ding, B. Cellulose Nanofibrous Membranes Modified with Phenyl Glycidyl 
Ether for Efficient Adsorption of Bovine Serum Albumin Advanced Fiber Materials 1 2019: pp. 1-9. https://doi.org/10.1007/s42765-019-00010-1

26. Pokatilov, F.A., Kizhnyaev, V.N., $\quad$ Zhitov, R.G., Krakhotkina, E.A. Network Polymers Based on Tetrazolylethyl Cellulose Ether Russian Journal of Applied Chemistry 89 2016: pp. 2102-2108.

https://doi.org/10.1134/S1070427216120259

27. Nagel, M., Koschella, A., $\quad$ Voiges, K., Mischnick, P., Heinze, T. Homogeneous Methylation of Wood Pulp Cellulose Dissolved in LiOH/urea/H2O European Polymer Journal 46 (8) 2010: pp. 1726-1735. https://doi.org/10.1016/j.eurpolymj.2010.05.009

28. Qian, L., Wu, P., Zhou, J., Zhang, L. Structure and Solution Properties of Cyanoethyl Celluloses Synthesized in LiOH/Urea Aqueous Solution Cellulose 19 2012: pp. $161-169$. https://doi.org/10.1007/s10570-011-9609-9

29. Dong, Y., Mosquera-Giraldo, L.I., $\quad$ Taylor, L.S., Edgar, K.J. Amphiphilic Cellulose Ethers Designed for Amorphous Solid Dispersion via Olefin Cross-Metathesis Biomacromolecules 17 2016: pp. 454-465. https://doi.org/10.1021/acs.biomac.5b01336

30. Sheiko, S.S., Sumerlin, B.S., $\quad$ Matyjaszewski, K. Cylindrical Molecular Brushes: Synthesis, Characterization, and Properties Progress in Polymer Science 33 (7) 2008: pp. $759-785$. https://doi.org/10.1016/j.progpolymsci.2008.05.001

31. Spiess, H.W. Macromolecular Engineering: Precise Synthesis, Materials Properties, Applications. Wiley-VCH Verlag, GmbH \& Co. KGaA, 2011: pp. 1937-1965. https://doi.org/10.1002/9783527631421.ch46

32. Abdelwahab, N.A., Ammar, N.S., Ibrahim, H.S. Graft Copolymerization of Cellulose Acetate for Removal and Recovery of Lead Ions from Wastewater International Journal of Biological Macromolecules 2015: pp. 913-922.

https://doi.org/10.1016/j.ijbiomac.2015.05.022

33. Jiang, F., Pan, C., Zhang, Y., Fang, Y. Cellulose Graft Copolymers Toward Strong Thermoplastic Elastomers Via RAFT Polymerization Applied Surface Science 480 2019: pp. $162-171$. https://doi.org/10.1016/j.apsusc.2019.02.210

34. Hirota, M., Tamura, N., Saito, T., Isogai, A. Water Dispersion of Cellulose II Nanocrystals Prepared by TEMPO-Mediated Oxidation of Mercerized Cellulose at $\mathrm{pH}$ 4.8 Cellulose 17 2010: pp. 279-288. https://doi.org/10.1007/s10570-009-9381-2

35. Wen, Y., Yuan, Z., Qu, J., Wang, C., Wang, A. Evaluation of Ultraviolet Light and Hydrogen Peroxide Enhanced Ozone Oxidation Treatment for the Production of Cellulose Nanofibrils ACS Sustainable Chemistry \& Engineering 8 2020: pp. 2688-2697.

https://doi.org/10.1021/acssuschemeng.9b06028

36. Singh, P., Duarte, H., Alves, L., Antunes, F., Medronho, B. Cellulose-Fundamental Aspects and Current Trends Chapters 1: From Cellulose Dissolution and Regeneration to Added Value Applications-Synergism Between Molecular Understanding and Material Development. InTech, Brazil, 2015.

https://doi.org/10.5772/61334

37. Singh, P., Magalhães, S., Alves, L., Antunes, F., Miguel, M., Lindman, B., Medronho, B. Cellulose-Based Edible Films for Probiotic Entrapment Food Hydrocolloids 88 2019: pp. 68-74. https://doi.org/10.1016/j.foodhyd.2018.08.057

38. Jamaluddin, N., Kanno, T., Asoh, T., Uyama, H. Surface Modification of Cellulose Nanofiber Using Acid Anhydride for Poly(lactic acid) Reinforcement Materials Today Communications 21 2019: pp. 100587.

https://doi.org/10.1016/j.mtcomm.2019.100587

39. Gao, H., Duan, B., Lu, A., Deng, H., Du, Y., Shi, X., Zhang, L. Fabrication of Cellulose Nanofibers From Waste Brown Algae and Their Potential Application as Milk Thickeners Food Hydrocolloids 79 2018: pp. 473-481. https://doi.org/10.1016/j.foodhyd.2018.01.023

40. Paximada, P., Tsouko, E., Kopsahelis, N., Koutinas, A.A., Mandala, I. Bacterial Cellulose as Stabilizer of $\mathrm{O} / \mathrm{W}$ Emulsions Food Hydrocolloids 53 2016: pp. 225-232. https://doi.org/10.1016/j.foodhyd.2014.12.003

41. Paximada, P., Koutinas, A.A., Scholten, E., Mandala, I.G. Effect of Bacterial Cellulose Addition on Physical Properties of WPI Emulsions. Comparison with Common Thickeners Food Hydrocolloids 54 2016: pp. 245-254. https://doi.org/10.1016/j.foodhyd.2015.10.014

42. Gibis, M., Schuh, V., Weiss, J. Effects of Carboxymethyl Cellulose (CMC) and Microcrystalline Cellulose (MCC) as Fat Replacers on the Microstructure and Sensory Characteristics of Fried Beef Patties Food Hydrocolloids 45 2015: pp. 236-246. https://doi.org/10.1016/j.foodhyd.2014.11.021

43. Bhatnagar, A., Sillanpää, M., Witek-Krowiak, A. Agricultural Waste Peels as Versatile Biomass for Water Purification - A Review Chemical Engineering Journal 270 2015: pp. 244-271. https://doi.org/10.1016/j.cej.2015.01.135

44. Hokkanen, S., Bhatnagar, A., Sillanpää, M. A Review on Modification Methods to Cellulose-Based Adsorbents to Improve Adsorption Capacity Water Research 91 2016: pp. 156-173.

https://doi.org/10.1016/j.watres.2016.01.008

45. Gopakumar, D.A., $\quad$ Pasquini, D., $\quad$ Henrique, M.A., Morais, L.C., Grohens, Y., Thomas, S. Meldrum's Acid Modified Cellulose Nanofiber-Based Polyvinylidene Fluoride Microfiltration Membrane for Dye Water Treatment and Nanoparticle Removal ACS Sustainable Chemistry \& Engineering 5 2017: pp. 2026-2033. https://doi.org/10.1021/acssuschemeng.6b02952

46. Abd El-Aziz, M.E., Kamal, K.H., Ali, K.A., AbdelAziz, M.S., Kamel, S. Biodegradable Grafting Cellulose/Clay Composites for Metal Ions Removal International Journal of Biological Macromolecules 118 2018: pp. $2256-2264$. https://doi.org/10.1016/j.ijbiomac.2018.07.105

47. Zhang, L., Hua, J., Zhu, W., Liu, L., Du, X., Meng, Y., Yao, M. Flocculation Performance of Hyperbranched Polyethylenimine-Grafted Cellulose in Wastewater Treatment ACS Sustainable Chemistry \& Engineering 6 2018: pp. $1592-1601$. https://doi.org/10.1021/acssuschemeng.7b02343

48. Gopi, S., Balakrishnan, P., Chandradhara, D. Poovathankandy, D., Thomas, S. General Scenarios of Cellulose and Its Use in the Biomedical Field Materials Today Chemistry 13 2019: pp. 59-78. https://doi.org/10.1016/j.mtchem.2019.04.012

49. Zhang, L., Wang, Y., Liu, H., Yu, L., Liu, X., Chen, L., Zhang, N. Developing Hydroxypropyl Methylcellulose/Hydroxypropyl Starch Blends for Use as Capsule Materials Carbohydrate Polymers 98 (1) 2013: pp. $73-79$. 
https://doi.org/10.1016/j.carbpol.2013.05.070

50. Zhang, X., Lin, F., Yuan, Q., Zhu, L., Wang, C., Yang, S. Hydrogen-Bonded Thin Films of Cellulose Ethers and Poly(acrylic acid) Carbohydrate Polymers 215 2019: pp. 58-62.

https://doi.org/10.1016/j.carbpol.2019.03.066

51. Dong, C., Ye, Y., Qian, L., Zhao, G., He, B., Xiao, H. Antibacterial Modification of Cellulose Fibers by Grafting $\beta$ cyclodextrin and Inclusion with Ciprofloxacin Cellulose 21 2014: pp. $1921-1932$. https://doi.org/10.1007/s10570-014-0249-8

52. Wang, W., Qin, C., Li, W., Ge, J., Feng, C. Improving Moisture Barrier Properties of Paper Sheets by Cellulose Stearoyl Ester-Based Coatings Carbohydrate Polymers 235 2020: pp. 115924.

https://doi.org/10.1016/j.carbpol.2020.115924

53. Muratore, F., Goñi, M.L., $\quad$ Serrano, L., $\quad$ Labidi, J., Barbosa, S., Martini, R. Biopolymer Grafting Synthesis and Properties Chapter 5: Development of Bioactive Paper by Capsaicin Derivative Grafting Onto Cellulose Elsevier 2018: pp. 199-233.

https://doi.org/10.1016/B978-0-323-48104-5.00005-6

54. Sun, B., Hou, Q., Liu, Z., Ni, Y. Sodium Periodate Oxidation of Cellulose Nanocrystal and Its Application as a Paper Wet Strength Additive Cellulose 2015: pp. $1135-1146$ https://doi.org/10.1007/s10570-015-0575-5

55. El-Wakil, N., Kassem, N.F., Hassan, M.L. Hydroxypropyl Cellulose/Rice Straw Oxidized Cellulose Nanocrystals Nanocomposites and Their Use in Paper Coating Industrial Crops and Products 93 2016: pp. 186-192. https://doi.org/10.1016/j.indcrop.2016.02.026

56. Shankar, S., Rhim, J. Antimicrobial Wrapping Paper Coated with a Ternary Blend of Carbohydrates (Alginate, Carboxymethyl Cellulose, Carrageenan) and Grapefruit Seed Extract Carbohydrate Polymers 196 2018: pp. 92-101. https://doi.org/10.1016/j.carbpol.2018.04.12

(c) Zhang et al. 2022 Open Access This article is distributed under the terms of the Creative Commons Attribution 4.0 International License (http://creativecommons.org/licenses/by/4.0/), which permits unrestricted use, distribution, and reproduction in any medium, provided you give appropriate credit to the original author(s) and the source, provide a link to the Creative Commons license, and indicate if changes were made. 